range of specified technically advanced products. Telecommunications equipment and Earth satellites are high on the US list at present, but they will become increasingly symbolic of last decade's technology. So, eventually, will be even supercomputers, one of the bones of US contention with Japan, in respect of which the Japanese government seems on the point of increasing the funds available to Japanese universities so that they will no longer have to depend on hefty discounts from Fujitsu for the purchase of these machines, but may buy full-price Crays instead.

Most probably, the administration is aware of all this, but feels trapped by the pressure from the Congress. It is even possible that the tough talking at the outset of the negotiations is designed to relieve the pressure from the Congress, thus allowing the administration to reach a reasonable accommodation with Japan.

But that is a risky strategy. It would be safer if the government tried to persuade its disparate constituents of the more substantial truth that the virtues of free trade are so great that they do not require reciprocity. If somebody else can sell manufactured goods or services more cheaply than they can be provided domestically, they constitute a bargain that should be jumped at. These days, there are all too many other things for idle hands to do.

\section{Unacceptable risk}

The reason why radiation may cause leukaemia in offspring should be pinned down as a matter of urgency.

THE managers of the British reprocessing plant for nuclear fuel at Sellafield have had a predictably torrid time in the past two weeks. The conclusion by Professor Martin Gardner and his colleagues that some cases of leukaemia in people under 25 may have been caused by their fathers' exposure to radiation at work (see Nature 343,$679 ; 1990$ ) could only have made more sharply poignant the decisions that those who work with radiation have always to make: will the small but non-zero extra risk be identifiable above the noise of mortality from natural causes among those exposed and of unspecific genetic defect among later generations? The trouble, with the now-plausible hypothesis that radiation exposure may occasionally be responsible for leukaemia among immediate offspring, is that the noise has been reduced virtually to zero. For at least some time, each male radiation worker who fathers a leukaemic child will jump to only one conclusion. Will nuclear plants now be able to recruit workers, and how?

The important letter from Dr J. H. Dunster on page 98 bears on that practical question as well as on the broader questions that have now been raised. Dunster, who retired only a year ago as director of the British National Radiological Protection Board, and who is now chairman of one of the sub-commissions of the International Commission on Radiological Protection (ICRP), presents only backof-the-envelope calculations. In the circumstances, nothing more elaborate is possible or justifiable. Gardner's study, after all, makes it quite plain that the association noted at Sellafield does not prove that radiation exposure causes leukaemia. And if there is such a link, there is nothing as yet to show whether what matters is a person's exposure in the few months before conception of a child or the accumulated dose, from natural and artificial radiation, since birth.

With all these reservations, Dunster's arithmetic shows that, if short-term dose is what matters, there is a one in 400 chance that a child fathered by a man exposed to 20 $\mathrm{mSv}$ of radiation will contract leukaemia. Rightly, he says the risk is "small, but not negligible". If, on the other hand, lifetime dose is what matters, the risk that a child will be leukaemic will be roughly the same if its father has been exposed to $200 \mathrm{mSv}$. Moreover, with the uncertain numbers arising from the Gardner study, if lifetime dose determines whether a leukaemic child is fathered, people's exposure to natural radiation may be a sufficient explanation of the occurrence of all leukaemia in the young.

The most urgent need is to discover whether the Gardner effect (if not just chance) is caused by the short-term radiation dose or by that accumulated over a lifetime. Luckily, there is much that research can do. Already there is some evidence of a linkage in the general population between paternal age and the occurrence of leukaemia among children, which implies an influence for the accumulated dose of natural radiation. If this linkage could be made quantitative by more extensive investigations, it would be possible to estimate the influence of accumulated radiation dose to male germ cells. That would at least allow the managers of nuclear plants and their employees to know what might be gained by opting out of radiation exposure temporarily.

The wider issues are those of the general management of radiation exposure. Natural radiation provides everybody with an annual dose of about $1 \mathrm{mSv}$ and the natural occurrence of leukaemia in the young (in Britain) is about 1 in 2,750 . If there is a causal relationship between radiation exposure and the occurrence of leukaemia, and if the numbers are those suggested by Dunster's provisional calculation, it is difficult to believe that the managers of nuclear plants will in future be able to regulate their affairs by yardsticks even as carefully devised as the latest proposals of ICRP, now in circulation in draft form.

Instead, it will be necessary to arrange that every employment interview is followed immediately by a counselling session, that workers at nuclear plants are not merely informed but also consulted about their radiation records and that the general exposure to radiation is further reduced. It is not that radiation risks have been grossly underestimated in the past, but that the Gardner study points to a weakness in the definition of what risks are acceptable. The principle has been that the consequences of exposure should be so unlikely that they are lost in the noise. If radiation causes leukaemia in offspring, even with a likelihood as small as one in 400 , the consequences will no longer seem inconspicuous to those concerned. 